\title{
Acceso exclusionario y racista a la vivienda formal e informal en las áreas centrales de Santiago e Iquique
}

\author{
Yasna Contreras Gatica \\ Universidad de Chile, Santiago, Chile. \\ Email: ycontrerasg@uchilefau.cl
}

\author{
Veera Ala-Louko \\ Universidad de Helsinki, Helsinki, Finlandia. \\ Email: veera.alalouko@gmail.com \\ Gricel Labbé \\ Universidad de Chile, Santiago, Chile. \\ Email: gricelabbec@gmail.com
}

\begin{abstract}
Resumen: ${ }^{1}$ La inmigración latinoamericana hacia Chile ha recobrado fuerza en los últimos años, imprimiendo una serie de cambios al menos en los espacios centrales donde muchos inmigrantes inician el proyecto migratorio. En su condición de inmigrante pobre, desplazado de sus localidades por guerras, conflictos civiles, inseguridad, o bien en su afán de progreso, arriban a sitios que hoy imponen nuevas fronteras simbólicas y materiales marcadas por formas exclusionarias y raciales de acceso a la vivienda que no necesariamente es formal, también más informal e ilegal. Los resultados de la investigación develan estrategias a las que incurren inmigrantes latinoamericanos en las áreas centrales de Santiago e Iquique. Se advierte un creciente mercado ilegal de acceso a la vivienda central, exclusionario y racista, que devela operaciones de propietarios que ven en el mercado informal de la vivienda mecanismos de ahorro y progreso material.
\end{abstract}

Palabras clave: inmigrante, mercado de la vivienda formal e informal y racismo.

\section{Racist and exclusionary access to formal and informal housing in central areas of the cities of Santiago and Iquique}

\begin{abstract}
Latin American immigration towards Chile has gain strength over the last years, pushing a series of changes, at least in central spaces where many migrants begin their migratory journey. In their condition of poor, displaced migrants, due to wars or conflict, insecurity, or even due to a dream of progress, they arrive to places which impose new symbolic and material frontiers, signed by exclusion and racialized access to housing, many times in illegal and informal terms. The result of this research reveal strategies used by Latin American immigrants in central areas of Santiago and Iquique to deal with a growing illegal housing market,
\end{abstract}


which reveals strategies of property owners which see in this an opportunity for savings and material progress.

Keywords: immigrant, housing market formal and informal, and racism.

\section{Acesso racista e excludente à habitação formal e informal em áreas centrais de Santiago e Iquique}

Resumo: A imigração latino-americana para o Chile recuperou força nos últimos anos, instaurando uma série de mudanças, pelo menos nas áreas centrais onde muitos imigrantes começam seu projeto migratório. Na sua qualidade de imigrante pobre, deslocados das suas aldeias por guerra, guerra civil, insegurança, ou em seu desejo de progresso, chegam a lugares que hoje impõem novas fronteiras simbólicas e materiais marcados por formas raciais e de exclusão do acesso à habitação. Elas não são necessariamente formais, mais também informais e ilegais. Os resultados da pesquisa revelam as estratégias em que incorrem os imigrantes latino-americanos nas áreas centrais de Santiago e Iquique. Adverte-seum crescente mercado de acesso ilegal à vivenda central, excludente e racista, que revela operações dosproprietários que têm no mercado informal de imóveis mecanismos de poupançae progresso material.

Palavras-chave: imigrante, mercado imobiliário formal e informal e racismo.

$* * *$

\section{Introducción}

En Latinoamérica uno de los movimientos más intensos desde la década de los años '90, está asociado a la movilidad de inmigrantes desde países vecinos como Perú, Bolivia, Colombia y en menor medida, República Dominicana. Sin embargo, más que hablar de países son determinadas localidades y ciudades de éstos países las que actúan como expulsoras y desplazadoras de personas, especialmente de menores ingresos. Chile se convierte en uno de los países de la región de mayor atracción migratoria. No obstante, el arribo de hogares y familias con movimientos socio-profesionales descendentes así como también, el deseo de mejorar las condiciones de vida en los lugares de migración, los limitan a un parque residencial central que es segregativo, informal, ilegal y racista. Por tanto, emergen nuevas formas de exclusión y formas de producción de hábitat popular que confirman que la formalidad no es la única manera de acceder a la vivienda para los hogares más pobres, especialmente inmigrantes latinoamericanos.

En los últimos años, los debates sobre la inmigración han buscado establecer relaciones entre causas, consecuencias y efectos en la sociedad de acogida, una vez que un individuo o un grupo familiar toma la decisión de partir. Sin embargo, interesa develar que en la construcción del proyecto migratorio la condición económica, étnica, racial, el origen e incluso, las especificidades y conflictos territoriales en las localidades de origen, hacen explícito que un movimiento de salida está marcado por un conjunto de factores y no por el determinismo del trabajo como factor exclusivo de 
salida. La inmigración está dominada por la búsqueda de equilibrio económico, afectividad, progreso, libertad, entre otras causalidades no lineales, que advierten que la inmigración hacia países como Chile exigen conocer las territorialidades y los contextos no sólo de los países atractores también, de las localidades de origen de los inmigrantes.

Lo que se desconoce tras un movimiento obligado o relativamente decidido es que el cambio de espacialidad y de sitio de vida, dispone al inmigrante a experiencias de cambios, reproducciones y reformulaciones (Stefoni, 2011; Imilán, Garcés, Margarit y Bijit, 2014) no sólo en el lugar de acogida, también en la forma de vincularse con la sociedad de origen (Imilán, Márquez y Stefoni, 2015). Es así como dentro de cada país existen espacios que resultan atractivos para los inmigrantes al inicio de su proyecto migratorio, generalmente los territorios más productivos.

Este artículo analiza la dimensión de acceso a la vivienda indistintamente de la etapa migratoria en la que se encuentren los entrevistados. Los espacios centrales y las ciudades productivas chilenas se vuelven objeto para el capital económico, de manera tal que se transforman en una especie de "faros" para individuos y familias que guían la decisión de migrar. Es así como dos ciudades chilenas una localizada al norte denominada Iquique, $\mathrm{y}$ otra capital del país Santiago se convierten en anclas y nodos para los sujetos aquí analizados. Lo paradojales que estas ciudades insertas en un contexto capitalista imprimen una imagen de sitios de progreso económico y aparente igualdad que no permea a los grupos inmigrantes que inician el proyecto migratorio o que se encuentran en la fase intermedia de éste. Esto último se explicaría en la necesidad del capital económico, comercial e inmobiliario de "encontrar espacios lucrativos para la absorción de excedentes de capital” (Harvey, 2008:17), espacios que quedan obsoletos o entran en disputa con aquellos demandados por hogares de menores ingresos.

Conjuntamente se busca analizar los mecanismos de acceso a la vivienda de inmigrantes latinoamericanos que arriban a las áreas centrales de las ciudades de Santiago e Iquique. La discusión se estructura en tres apartados: el primero plantea una discusión teórica sobre informalidad e ilegalidad en el acceso a la vivienda, a objeto de vincularlo con los mecanismos de acceso exclusionario al espacio central de inmigrantes latinoamericanos que habitan en condición de precariedad. La segunda parte está orientada a los resultados de la investigación, identificando lógicas y mecanismos exclusionarios de acceso a la vivienda. Se parte del supuesto que la condición racial y el origen del inmigrante latinoamericano lo vuelve un sujeto excluido del sistema formal de acceso a la vivienda, especialmente los inmigrantes negros. El tercer apartado y final, tiene como objetivo reflexionar sobre el rol de las políticas públicas en la producción de viviendas en alquiler para hogares inmigrantes y nativos de bajos ingresos que apelan a una vida central.

Metodológicamente, la investigación tiene un sustento cuantitativo derivado de la aplicación de 312 encuestas en las áreas centrales de Santia- 
go e Iquique, donde habitaran hogares de bajos ingresos. Se realizaron 173 encuestas a hogares de ingresos bajos y muy bajos en cinco barrios de la comuna de Santiago; y 139 encuestas en cinco áreas de mayor concentración de hogares pobres en la comuna de Iquique. De éste conjunto, 52 encuestas correspondieron a inmigrantes latinoamericanos para las dos áreas centrales. En Iquique, de los encuestados (18 inmigrantes) el 44,4\% eran peruanos, 38,9\% bolivianos, $11,1 \%$ colombianos, y 5,6\% ecuatorianos. En Santiago, el 73,5\% eran peruanos, 8,8\% colombianos, 12\% se dividían entre argentinos, ecuatorianos, y de otros países de Latinoamérica. Dada las dificultades para conocer formas de acceso exclusionario a la vivienda informal se realizaron entrevistas en profundidad tanto en Santiago como en Iquique, reconociendo también, que muchos arrendadores, intermediarios y administradores de viviendas tugurizadas restringían el acceso al equipo investigador, y condicionaban las posibilidades de los relatos. De 34 encuestas a inmigrantes en Santiago se efectuaron 10 entrevistas a inmigrantes, principalmente peruanos y colombianos. En Iquique de las 18 encuestas se lograron realizar 8 entrevistas en profundidad a colombianos, peruanos, bolivianos y dominicanos. Del total de entrevistados, la mitad tenía permanencia definitiva (5 casos), otros tenían visas temporal (6) y el resto no declaraba documentos. Las entrevistas fueron aplicadas en diferentes momentos, durante julio 2013, Enero y Mayo 2014, dada las limitantes de los inmigrantes en cuanto a entregar información sobre sus condiciones de habitabilidad, las características de los arrendadores, y los mecanismos de acceso a la vivienda. Asimismo se intentó entrevistar a arrendadores o administradores a objeto de identificar las exigencias que realizan a los arrendatarios y subarrendatarios. En Iquique sólo un administrador inmigrante accedió a entregar información. En Santiago se entrevistaron dos inmigrantes que cumplían con el rol de ser arrendatarios e intermediarios de los propietarios. La pauta de entrevista buscó conocer las formas de acceso a la vivienda y las limitantes que encuentran los inmigrantes según nacionalidad, color y condición laboral.

\section{Ser pobre y acceder a una vivienda informal e ilegal en el espacio central}

Durante la década de los años '70 y 80 en Latinoamérica se desarrolló una discusión sobre las variadas formas de producción del hábitat popular (Clichevsky, 1975; Smolka, 1981; Jaramillo, 1982). No obstante, en los años '80 el acceso al espacio urbano y las formas de producción del hábitat en áreas centrales como periféricas tensionaba por antonomasia los conceptos legalidad-ilegalidad, formalidad-informalidad y/o regularidad-irregularidad (Azuela, 1993; Rolnik, 1996; Duhau, 1995; Calderón, 1999)aunque en dicho contexto, la migración interna era dominante por sobre la externa, salvo algunas excepciones a nivel país.

La informalidad, que tradicionalmente ha sido visto como una consecuencia directa de la pobreza (Banco Mundial 2006, citado en Smolka \& 
Biderman, 2011) y parte de la urbanización de ella (UN-HABITAT, 2003), surge en esta discusión como una lógica de producción del espacio urbano (Abramo, 2008; 2012) y como forma de acceso a tierra en conflicto en el orden estatal (Canestraro, 2013). A su vez, la informalidad emerge como estrategia de los hogares de bajos ingresos ante la falta de alternativas (Mac Donald, 2011; Gilbert, 2000;Carrión, 1992) de acceso a viviendas dignas, acordes a las necesidades y presupuestos familiares.

En la investigación urbana latinoamericana, el término informal ha sido intercambiable con conceptos tales como irregular, ilegal y clandestino $^{2}$, lo cual crea una paradoja teórica (Calderón, 1999) y dificulta el entendimiento y uso de dichos categorías. Por otro lado, se ha establecido una definición por la negación ${ }^{3}$ (Cardoso, 2003, citado en Canestraro 2013), donde la informalidad se entiende a través de consideraciones sobre la formalidad y así es definido por su negación respecto a lo que no es (Clichevsky, 2003). Por tanto, cuando se alude a informalidad en el acceso a la vivienda, el término se vuelve descriptivo más que exacto y preciso. Sin embargo, todas las dimensiones parecen asumir una situación en conflicto con la normativa estatal vigente en una sociedad (Azuela, 1993; Duhau, 1995), planteando la dimensión jurídica como algo intrínseca (Calderón, 1999) y sugiriendo que son las normas y procedimientos estatales que califican, establecen y acotan el fenómeno de estudio y al mismo tiempo, la tolerancia y la regularización de él (Cruz, 2000). Chile no escapa de esta lógica, ya que sus espacios centrales y pericentrales concentran un parque residencial de viviendas tugurizadas donde los propietarios -residentes y no residentes- se desligan del cuidado de dichos inmuebles, amparados por normas que no establecen responsabilidades. Se favorece así, un mercado informal e ilegal de acceso a la vivienda central creciente y desigual (Contreras, 2012; Márquez, 2013; Margarit y Bijit, 2014; Contreras y Calorio, 2015).

Así la dialéctica de lo informal y lo formal no se define ni conceptualiza en profundidad. Más bien, se entiende el fenómeno como un parte de la lógica sistémica estatal capitalista en sí misma (Fernándes, 2002, Rolnik, 1996), en tanto en el marco normativo que pretende organizar el espacio de la ciudad no hay lugar para los sectores de menores recursos y por ende, la informalidad es parte (Rolnik, 1996) resultante de dicho proceso como una modalidad y estrategia para aquellos que no pueden cumplir con las normativas estatales o no han sido considerados en ellas.

Definir lo informal como lo no integrado al sistema que se considera convencional (Riofrío, 2001, citado en Clichevsky, 2003), no supone adherir a una taxonomía dual entre lo formal versus lo informal, por cuanto la informalidad es parte constituyente de la estructura productiva y territorial (Herzer et al., 2014). Desde su origen conceptual histórico, la informalidad resultade una relación dialéctica entre capital y trabajo, especialmente de los grupos que no lograban insertarse en la economía moderna. La informalidad no se limita a ser entendida como una exclusión en el sentido normativo, sino que constituye una parte de la producción de la ciudad y una lógica de cómo 
acceder a ella. Por lo tanto, más que describir un estado, la informalidad debe ser entendida como una acción, una práctica y un proceso al que recurren aquellos invisibilizados.

Se puede pensar la informalidad por medio de una lógica de necesidad en el marco de la producción de ciudad, que según Abramo (2008; 2012) es una lógica social de acceso a la tierra urbana que contribuye a su formación socio-espacial, coexistiendo y confluyendo en el espacio y el terreno urbano con las otras dos lógicas: la lógica del mercado y la del Estado. En este escenario, lo informal y lo formal coexisten geográficamente, formando una estructura interdependiente (Smolka \& Biderman, 2011). El precio excesivamente alto de la tierra urbanizada en América Latina y el mal funcionamiento del mercado tierras, como el no considerar las necesidades sociales, y la práctica de mantener tierras vacantes intencionalmente, son algunos de los factores que dificultan el acceso a la tierra urbana especialmente de los sectores de bajos ingresos (Smolka, 2003). En Chile, las limitantes aún están sustentadas en la escasez del suelo como mecanismo de capitalización solo para los mejores pagadores del suelo.

La ciudad formal moderna por tanto, impone un conjunto de requisitos normativos y produce una barrera institucional a la provisión de vivienda para los sectores populares (Abramo, 2012). Por un lado, la producción capitalista de vivienda no se ha desplegado de manera plena en el mercado, ni ha podido ofrecer vivienda a los más pobres (Jaramillo, 2008). Del otro lado, las políticas habitacionales públicas no han sido capaces de incluir a los habitantes populares a la ciudad formal: en Chile, mientras la política de provisión habitacional ha reducido de forma sustantiva el déficit habitacional nacional (Sabatini, 2003, Gilbert 2002) y fue celebrada y replicada en varios países latinoamericanos y en otros regiones del Sur por su éxito (Gilbert, 2002; 2004), se han presentado críticas a la política habitacional, argumentando que las viviendas de interés social no están adaptadas a los modos de vida y a las necesidades de los sectores populares, identificando así la paradoja de los “con techo" y un proceso de informalización de lo formal a través de sus intentos de adaptarse y responder a sus necesidades (Rodríguez \& Sugranyes, 2004). Incluso, si se cuestiona quiénes tienen derecho a la vivienda formal, los inmigrantes latinoamericanos se ven más limitados al accesoa la vivienda.

\section{Ser pobre, inmigrante y negro en el acceso a la vivienda formal e informal}

Tanto los nativos como los inmigrantes internos y externos de bajos ingresos, han estado históricamente condenados a habitar en espacios tugurizados y hacinados. Sin embargo, es sorprendente que en las sociedades actuales que se autodefinen inclusivas o al menos apelan a ello, el racismo y la legalidad del ser humano sean rasgos de retorno hacia formas exclusionarias. Aún más, en la sociedad chilena la formalidad en el acceso a 
la vivienda es un mecanismo de progreso social y material. La formalidad tiende en los últimos cuarenta años a producirse mayoritariamente en los espacios periféricos de las ciudades chilenas. Por tanto, cabría cuestionarse qué ha sucedido en términos de vivienda en los espacios centrales y pericentrales, y porqué la tugurización y el hacinamiento vuelven a ser temas conflictivos y recursivos.

La condición de tugurización en Latinoamérica no es un fenómeno nuevo ni menos es responsabilidad de los más pobres. Más bien, emerge cuando las condiciones de habitabilidad no son las más adecuadas dado la condición de vulnerabilidad y escaso apoyo del Estado hacia estos grupos. Desde los años '20 la tugurización responde a la forma tradicional por medio de la cual sectores populares acceden a mercados de la tierra y de vivienda de forma irregular. El tugurio opera como colchón de resistencia frente a la demanda masiva de vivienda, sobre la base de costos relativamente baratos por ser una oferta que se basa en la utilización intensiva de los soportes materiales previamente producidos y no de la producción de nuevos. Esto resulta de un proceso social en el cual los sectores populares se ven obligados a incrementar el uso social del espacio (hacinamiento y la densificación) a cambio del control de una ubicación que les permita bajar sus costos residenciales y las distancias a los ámbitos productivos(Carrión, 2004). La conformación de tugurios responde finalmente, a un "camino para acceder a la tierra y la vivienda en contextos donde no es posible hacerlo de otra forma” (Mac Donald, 2011:17). Esto último, es lo que refleja en parte las demandas residenciales de inmigrantes latinoamericanos que no pueden acceder a una vivienda digna.

En el contexto actual donde los espacios centrales no son exclusivamente demandados por grupos de altos ingresos, sino más bien por grupos diversos en términos de educación, orígenes residenciales, tamaños familiares, entre otros, lo que emerge es la confluencia de un mercado dual de vivienda - el mercado formal y el mercado informal (Abramo, 2012) (Imilán, Márquez y Stefoni, 2015). Detrás de ese mercado dual surgen nuevas formas de tugurización, pero mucho más complejas que las descritas en los años '60, 70'o '80. El mercado informal de la vivienda por consecuencia, ofrece a los habitantes de bajos ingresos oportunidades económicas importantes en comparación con los productos ofrecidos por los programas públicos de vivienda de interés social, entre ellos la rentabilidad de alquiler y la existencia de comercios y servicios, así como la ubicación, conectividad y la proximidad a servicios en relación con las redes y lazos sociales (Abramo, 2010) que dan sustento a su vida cotidiana. Estas condiciones son características del tipo de alojamiento tugurizado y hacinado demandando en las áreas centrales de ciudades productivas como en Santiago e Iquique (Granados, 2009; Contreras, 2011, 2012; Stefoni, 2011, Margarit y Bijit, 2014), pero también están fuertemente determinadas por la llegada de inmigrantes latinoamericanos que llegan al país por diferentes causas, siendo el centro un sitio de referencia a partir del cual se establecen múltiples relaciones espaciales y sociales. 
Los inmigrantes latinoamericanos demandan viviendas compartidas en alquiler y subalquiler (Smolka \& Biderman, 2011; Di Virgilio et al. 2014) en espacios centrales y pericentrales asociado a la oferta de viviendas con bajos niveles de habitabilidad (Abramo, 2010). Los tugurios comprenden viviendas carentes en acceso a agua potable y a saneamiento, durabilidad de vivienda, tamaño de la habitación, calidad de los muros, entre otros rasgos que dominan los tugurios observados en Santiago Centro y en algunas manzanas de Iquique (Contreras y Calorio, 2015). Nadie se hace responsable por la recuperación de los inmuebles en su interior, y escasamente existen normativas que traspasen esas externalidades y costos a sus propietarios. Estas nuevas formas de tugurización son el reflejo de una sociedad que invisibiliza a los pobres, favoreciendo la especulación de mejores pagadores del suelo. En consecuencia, los inmuebles tugurizados se convierten en sitios estratégicos para los más pobres (Carrión, 2004) y para un mercado informal de comercialización creciente y desigual.

\section{Inmigrantes latinoamericanos relegados a viviendas deterioradas, tugurizadas y hacinadas en las áreas centrales de Santiago e Iquique}

Los inmigrantes latinoamericanos que arriban a las áreas centrales de Santiago e Iquique tienden a localizarse en aquellos sectores donde existe un parque residencial deteriorado que asegura el acceso. Los hallazgos aquí presentados resultan de una investigación Fondecyt realizada durante los años 2012-2015. Conjuntamente se espacializan y analizan las direcciones de residencias declaradas por los inmigrantes al Departamento de Extranjería (DEM), especialmente para los años 2012, 2013,2014. Estos datos constituyen los más actualizados en referencia a los resultados de los Censos 1992, 2002 o 2012. Los resultados de ambas fuentes (Fondecyt y DEM) develan que los inmigrantes latinoamericanos se localizan en los mismos sitios donde habitaron inmigrantes internos de otras épocas. Por inmigrantes latinoamericanos se consideran sólo aquellos que resultaron del cuestionario Fondecyt en específico peruanos, colombianos, bolivianos, dominicanos y ecuatorianos. En el caso de Iquique los inmigrantes residen en los sitios de localización de los pampinos que accedieron a la propiedad a través de tomas irregulares a fines de los '60 (Márquez, 2013, Labbé, 2015; Calorio, 2015; Contreras y Calorio, 2015). En Santiago Centro habitan en los barrios Balmaceda y Yungay, mayoritariamente, o bien en algunos pasajes y antiguos conventilllos (Granados, 2009; Contreras, 2012) de los barrios Lira y Almagro.

Estudiar las áreas centrales de Santiago e Iquique radica exclusivamente en ser los primeros espacios donde arriban los hogares o individuos inmigrantes. Asimismo las áreas centrales son los sitios de concentración de oportunidades laborales, servicios urbanos, intermodalidad, entre otros (Turner 1968, citado en Coulomb, 2010 y en Gilbert \& Crankshaw, 1999). Sin embargo, la espacialización de los sitios declarados por los inmigrantes 
como lugares de residencia evidencian por ejemplo, que en la ciudad de Iquique entre los años 2009 y 2010 emergen nuevos frentes de localización residencial, sobrepasando los límites del centro. Las nuevas ofertas se localizan en la zona pericentro poniente y sur donde existe un parque de viviendas con posibilidades de densificarse, hacinarse y transarse bajo lógicas ilegales de acceso al subalquiler.

De manera específica, y desde una dimensión histórica más del 65\% de las permanencias y visas entregadas entre los años 2002 a 2012 se concentraron en la ciudad de Iquique, y de éstas más del 21\% corresponden a permanencias y visas entregadas a inmigrantes que declaran residencia en el centro (barrio Boliviano, y en menores casos en la Población Jorge Inostroza) y pericentro de la ciudad (Población Teniente Ibañez y Caupolicán). Los inmigrantes en Iquique habitan entre dos mercados: el del Agro en el pericentro sur, y en torno a los ejes comerciales tradicionalmente ubicados en el barrio Boliviano o mercado tradicional. Por tanto, todos los inmigrantes estudiados buscan articular trabajo, vivienda y familia. En el caso de la comuna de Santiago los inmigrantes latinoamericanos originalmente habitaban en los barrios Yungay, Brasil, Balmaceda y algunas manzanas del centro de Santiago. Sin embargo, a medida que el capital inmobiliario compraba antiguas residencias para construir edificios en altura y se saturaba la oferta de viviendas tugurizadas, aumentando también el costo de alquiler y subalquiler, los inmigrantes se desplazaron hacia los barrios Lira y Almagro donde aún existe un parque residencial en deterioro, que asegura oportunidades de acceso a viviendas hacinadas con precios relativamente inferiores respecto a los espacios tradicionales de localización de inmigrantes (Contreras, 2012).

\section{Códigos y lógicas de la informalidad en el acceso a la vivienda central para inmigrantes latinoamericanos: Alquilando y sub-alquilando a través de intermediarios}

Los 18 inmigrantes entrevistados tanto en Santiago (10) como en Iquique (8) habitan en diferentes tipos de inmuebles. En Iquique por ejemplo, acceden a viviendas y piezas que subarriendan en un parque residencial deteriorado y tugurizado. Algunos viven en los segundos pisos de usos comerciales, bodegas y pequeños talleres del centro. Otros en cambio, a medida que conocen la ciudad o tienen contactos, acceden a viviendas de no más de $50 \mathrm{~m}^{2}$ en la Población Teniente Ibañez y Caupolicán en el pericentro sur de Iquique. En la comuna de Santiago los entrevistados habitan en: piezas o casas en residencias antiguas de uno a dos pisos; en piezas subarrendadas en cités; en piezas o casas compartidas con familiares al interior de pasajes, y en menores casos, en casas antiguas en torno a los barrios Brasil, Yungay y en menor medida en Bogotá.

Tras las razones de concentración de los inmigrantes en torno a las áreas centrales, el parque inmobiliario antiguo en el centro responde a la creciente demanda de vivienda en alquiler y subalquiler como una solución 
habitacional para los grupos de menores ingresos (Abramo, 2010), aunque disputan ese espacio con antiguos hogares nativos de bajos ingresos que heredaron inmuebles y que hoy ven en el mercado de la renta una forma de inversión. En las áreas de estudio, existe un parque residencial con diferentes tipos de viviendas las cuales son subdividas de casas a cuartos en alquiler con servicios sanitarios, lavaderos y patios compartidos.

Mientras la propiedad es considerada como la tenencia natural para una parte de la sociedad de consumo y una parte integral de un Estado de bienestar (Gilbert, 2008), el alquiler y subalquiler es una respuesta rápida para obtener vivienda y no implica compromisos financieros ni espaciales a largo plazo (Kumar, 2001, citado en Briceño-León 2010) para los propietarios y administradores. Es así, como el arriendo y subarriendo, emerge como una solución lógica para los inmigrantes y como una situación transitoria sustentada en el imaginario del retorno o bien, limitada por el deseo de volverse propietarios de un inmueble una vez integrada a la sociedad del país de destino, y al mercado laboral. Sin embargo, las posibilidades de los inmigrantes están restringidas a las condiciones de acceso a la vivienda en la medida en que mantienen su condición de irregularidad.

El Ministerio de Vivienda y Urbanismo (MINVU) en el año 2014 dio pequeñas señales en tanto familias inmigrantes residentes en Chile que: "deseen acceder a diferentes subsidios para comprar viviendas de interés social sólo deberán tener el documento de residencia definitiva, el que se obtiene luego de 5 años de permanencia en el país pero sin sumarles otros 5 años para demostrar antigüedad" 4 . Pese a ese pequeño avance, la atención a la vivienda del inmigrante se centra nuevamente en lo "formal, lo regular" o legal, pero ¿qué sucede con aquello que no está inserto en ese mundo?. El desafío del Estado y de los gobiernos locales es prestar atención a la informalidad e ilegalidad en el acceso a la vivienda, dado que éste opera con códigos y lógicas similares a la formalidad, pero disfrazadas detrás de la fachada:

"Un lío para buscar casa para extranjeros tienes que tener un aval, que te respalde un chileno sino no te van a alquilar aunque tengas el dinero. Hay lugares donde no te piden papeles ni nada, pero te hacen exigencias no sé por qué” (mujer ecuatoriana, área central de Iquique)

"Casi no pudimos arrendar porque era muy difícil, nos tocó dejar garantía de 4 meses, nos tocó pagar como 800.000(US\$ 5525). Además, aquí en Chile ser colombiana es como estar enfermo, te discriminan mucho y cuesta entrar a una pieza. Te cambian el precio cuando quieran”(mujer colombiana, área central de Iquique)

Frente a la situación habitacional de los inmigrantes y las limitantes que encuentran para cumplir con las normativas impuestas en una sociedad 
formal, devienen subarrendatarios por restricción (Peppercorn \& Taffin 2013: 13). Muchos de los entrevistados ahorran más del $60 \%$ de sus ingresos para enviarlos a sus lugares de origen como remesas, por tanto el subarriendo y la informalidad en el acceso, se convierte en una lógica y estrategia de acceso a la ciudad y en estrategia de ahorro para apoyar a sus familias. El hecho de no solicitar documentación favorece prácticas exclusionarias, discriminatorias de acceso a la vivienda, reflejadas en exigencias en cuanto a compartir espacios comunes, subdividir espacios informales o no acondicionados como vivienda o cambiar el valor del subalquiler en cualquier momento. Es aquí donde el administrador o intermediario entre el inmigrante y el propietario juega un rol clave, como sujeto especulador. En este mercado de acceso informal a la vivienda, incluso ilegal el intermediario puede ser: un propietario arrendador, un administrador nativo o inmigrante; un intermediario inmigrante subarrendatario.En el Cuadro $\mathrm{N}^{\circ} 1$ se concluye lo que hace diferente al administrador del intermediario. El primero tiende a ser contratado por el propietario, recibiendo regularmente una mensualidad. En cambio, el intermediario tiende a ser escogido por el administrador, percibiendo rentas irregulares o bien, siendo liberado del pago del subalquiler. Esta condición lo posiciona como uno de los sujetos más arbitrarios haciendo cobros adicionales, o arbitrarios a algunos inmigrantes. Estas prácticas son generalmente desconocidas por el propietario, e incluso en menores casos por el administrador. El intermediario responde esencialmente a un inmigrante peruano con más de 10 años en Chile.

"Fuimos a alquilar una pieza chica, en una casona, pero en esa casona la dividieron en dos y la hicieron altillo, mi cuñado, que vive arriba, ellos vivían ahí, y... entonces ellos me subarrendaron. Así funciona esto en Chile”.

El análisis de las condiciones de vida y habitabilidad de los inmigrantes en un parque de vivienda informal y creciente, advierte también la organización interna y los reglamentos de comportamiento a los que deben acogerse:

"Antes tuvimos problemas y peleas con compatriotas nuestros, porque querían prender música, ponerse a chupar, entonces no puede ser así porque esto es chico, todos estamos pegados, y al otro día hay que trabajar. Acá yo no permito esto. Arriba hay unos arrendatarios, son piezas, ella la dueña me dijo que fuera el encargado de tratar con los arrendatarios, pero da algo de plata (inmigrante peruano, área central de Santiago, arrendatario e intermediario arrendador).

Tras las entrevistas se evidencia un régimen informal e ilegal de acceso a la vivienda en las dos áreas centrales estudiadas. Lo anterior, resulta de la combinación de tres factores: por un lado, su condición de inmigrante irregular; en segundo lugar, la ausencia de ofertas residenciales formales y asequibles económicamente en espacios centrales y 
pericentrales para inmigrantes, por cuanto en Chile todo se formaliza y el arriendo se observa como barrera de progreso y movilidad. La tercera causa explicativa, resulta de la alta demanda de localización de inmigrantes de menores ingresos en espacios centrales, las que ofrecen mayores posibilidades de desarrollar y viabilizar su proyecto migratorio al menos en las etapas iniciales.

\section{Cuadro Nº1. Caracterización del mercado habitacional informal en Santiago e Iquique}

\begin{tabular}{|c|c|c|c|c|}
\hline \multirow[t]{2}{*}{ OFERENTE } & \multirow{2}{*}{ DEMANDA } & \multirow{2}{*}{ EXIGENCIAS } & \multirow[b]{2}{*}{$\begin{array}{l}\text { ESTRATEGIA } \\
\text { A LA QUE } \\
\text { RECURRE EL } \\
\text { INMIGRANTE }\end{array}$} & \multirow[b]{2}{*}{$\begin{array}{l}\text { RESPONSABILIDAD } \\
\text { DEL OFERENTE } \\
\text { (propietario, } \\
\text { administrador } \\
\text { intermediario } \\
\text { inmigrante) }\end{array}$} \\
\hline & & & & \\
\hline $\begin{array}{l}\text { Propietario } \\
\text { Arrendador } \\
\text { Administrador } \\
\text { Generalmente. } \\
\text { tanto el arrendador } \\
\text { como el } \\
\text { administrador } \\
\text { tienen contratos } \\
\text { formales con el } \\
\text { propietario }\end{array}$ & \multirow{2}{*}{$\begin{array}{l}\text { Inmigrante sin } \\
\text { permanencia } \\
\text { Inmigrante con visa } \\
\text { temporaria } \\
\text { Inmigrante formal } \\
\text { buscando trabajoo } \\
\text { contrabajos precarios } \\
\text { Mujeres inmigrantes } \\
\text { conniños }\end{array}$} & $\begin{array}{l}\text { Pago del alquiler o } \\
\text { sub-alquiler con } \\
\text { precios variables }\end{array}$ & $\begin{array}{l}\text { Algunas familias } \\
\text { o amigos escogen } \\
\text { alinmigrante que } \\
\text { tiene trabajo } \\
\text { formal quien } \\
\text { actúa como } \\
\text { intermediario } \\
\text { entre el } \\
\text { propietario o } \\
\text { administrador }\end{array}$ & \multirow{2}{*}{$\begin{array}{l}\text { Es responsabilidad del } \\
\text { intermediario o } \\
\text { administrador sólo cobrar } \\
\text { el alquiler o subalquiler } \\
\text { Los valores de alquiler y } \\
\text { sub-alquiler son definidos } \\
\text { por propietarios y } \\
\text { aumentados por } \\
\text { administradores e } \\
\text { intermediarios } \\
\text { (informales o formales) } \\
\text { El propietario, } \\
\text { administradoro } \\
\text { intermediario no es } \\
\text { responsable de la } \\
\text { mantención de } \\
\text { electricidad, salubridad, } \\
\text { estado de muros, } \\
\text { filtraciones, daños en } \\
\text { baños, recolección de } \\
\text { basuras, entre otros }\end{array}$} \\
\hline $\begin{array}{l}\text { Intermediario } \\
\text { (generalmente es } \\
\text { uninmigrante que } \\
\text { cumple las } \\
\text { funciones del } \\
\text { administrador, } \\
\text { siendo elegido en } \\
\text { la mayoria de los } \\
\text { casos por éste y no } \\
\text { por el propietario) }\end{array}$ & & $\begin{array}{l}\text { Cada persona que sub- } \\
\text { alquila paga el costo } \\
\text { de subariendo de la } \\
\text { pieza, y los valores de } \\
\text { son variables, sujetos } \\
\text { a los valores } \\
\text { arbitranios } \\
\text { establecidos porlos } \\
\text { intermediarios }\end{array}$ & $\begin{array}{l}\text { Inmigrantes } \\
\text { negros (todos } \\
\text { asimilados como } \\
\text { colombianos) } \\
\text { tiendenrecumir a } \\
\text { inmigrantes } \\
\text { peruanos como } \\
\text { mecanismo de } \\
\text { acceso al sub- } \\
\text { alquiler }\end{array}$ & \\
\hline
\end{tabular}

Fuente. Elaboración propia a partir de entrevistas con arrendatarios y arrendadores. Encuesta y Entrevistas Fondecyt de Iniciación №11121241, 2013.

A su vez, en el caso de la lógica del mercado participan dos actores básicos: en un primer momento, un oferente y un demandante dentro de una relación generalmente asimétrica en donde el primero tiende a imponer sus condiciones al segundo gracias a la informalidad y/o ilegalidad del acuerdo celebrado y/o a la situación irregular de permanencia del inmigrante. Sin embargo, existiría un tercer actor en una posición intermedia (Cuadro $\mathrm{N}^{\mathrm{0}} 1$ ) que aprovechando su situación de pionero en el arribo a la ciudad, zona y/o vivienda, cumple la función de administrar una casa subdividida en nombre del dueño original a cambio de un salario, o de emprender un negocio de subarriendo, modificando una vivienda previamente arrendada sin el conocimiento y/ consentimiento del 
dueño del inmueble, manteniéndose de este modo la misma asimetría de poder que en el primer caso. En ambos casos, los actores participantes de esta relación de mercado no presentan, en su mayoría ni el mismo país de origen ni algún vínculo de parentesco o cercanía, aunque el arribo y conocimiento de la oferta de arriendo, subarriendo y/o compra se produce generalmente gracias a la existencia de una red de contactos los que a través de los datos "boca a boca" dan cuenta de las oportunidades que existen. Lo anterior implica que se está en presencia de un mercado imperfecto debido a la carencia de una plataforma de información exhaustiva y de fácil acceso a todas las ofertas posibles a las que puedan acceder los inmigrantes.

Considerando el cuadro 1 en cuanto a las condiciones de acceso al mercado informal de la vivienda, la mayoría de los entrevistados entre los cuales algunos representan a los propietarios y se vuelven intermediarios o administradores de los inmuebles-, declaran que es relativamente fácil acceder al sub-alquiler, pero lo complejo es cómo cambian las condiciones de habitabilidad y subarriendo conforme pasa el tiempo. Los arrendadores, administradores o intermediarios no se hacen responsables de las condiciones de habitabilidad, del estado de la electricidad, la materialidad de los inmuebles, los riesgos de incendios, entre otros. Todo se externaliza al inmigrante subarrendatario o arrendatario. Existe además, arbitrariedad en cuanto al valor del alquiler y subalquiler. Este mercado imperfecto es regulado sólo por el propietario, el administrador y en muchos casos, el intermediario aumenta los valores en función de las condiciones materiales y poder de negociación con cada inmigrante. Todo se complica cuando el inmigrante es negro o cuando son mujeres con niños.

“También era una casona grande, una casona en que siempre alquilan las piezas y habían como más de treinta familias, todas compartían el baño, la cocina” (inmigrante peruana, área central de Santiago).

“Me cambian el valor de mi pieza no sé por qué razones. Además me ha costado mucho encontrar algo digno, porque tengo niños y se me cierran las puertas (inmigrante, dominicana, area central de Iquique”.

Nunca he sabido quién es quién me arrienda esta pieza. A veces es un compatriota, otras veces aparece el dueño pero no podemos hablar con él (inmigrante, peruano, area central de Santiago).

"En Chile te miran la cara y el color de piel. Según eso te van dando precios de arriendo”. Yo vivo ahorita en la Cruz Fernández con José Miguel Carrera pero he vivido la cuestión de la discriminación tanto así que no he podido conseguir una casa (inmigrante colombiano, residente en el centro de Iquique) 
Este proceso se caracteriza en general, por lo que acontece cuando "los ocupantes pagan alquiler y con frecuencia una renta en niveles relativamente bajos, que en algunas ciudades es controlada por la legislación, pero por lo general a niveles por debajo del costo económico de mantener adecuadamente el edificio y sus servicios. Este política de alquiler de congelación es ampliamente reconocida como una contribución al deterioro de las casas de estos espacios, ya que no es rentable para los propietarios invertir en el mantenimiento de propiedades” (UNHSP 2003:80). Es decir, esta ulitización de espacios a precios relativamente bajos, funciona para usuarios de escasos recursos, por lo que no existe una inversión en la recuperación de las viviendas, lo que promueve el deterioro de su infraestructura e incluso, expone a inmuebles antiguos en zonas de verticalización a procesos de gentrificación con desplazamientos directos o indirectos (Contreras, 2012).

Respecto a los valores de alquiler y subalquiler de piezas, el aumento de éstos en barrios consolidados por inmigrantes como es el caso de la comuna de Santiago, vuelve el acceso a la vivienda incluso informal, más restrictiva. En la Figura $\mathrm{N}^{\circ} 1$ se exponen los valores de arriendo formal e informal de piezas en el área central de Santiago. Lo formal se vincula a aquellos casos donde los entrevistados declaraban haber firmado contratos, aunque ninguno de ellos lo exhibió al momento de la entrevista, declarando haberlo perdido. Si bien la mayoría de las ofertas son menores a $\$ 140.000$ para piezas de hasta $20 \mathrm{~m}^{2}$, existen algunas manzanas próximas a los barrios centro histórico, Balmaceda, Lira y Almagro con valores superiores a \$160.000 lo que explica por dos causas: piezas con posibilidades de tener cocinas en su interior, o bien por la demanda existente frente a otras zonas donde las ofertas están consolidadas.

En el caso del área central de Iquique, los valores más altos de arriendo de piezas oscilan entre \$140.000 a \$60.000 en torno a Plaza Arica y las poblaciones Teniente Ibáñez y O’Higgins. Existen algunas manzanas del centro y pericentro que alcanzan valores hasta $\$ 200.000$ (US\$640,0), especialmente hogares de bajos ingresos que habitan en residencias menores a $80 \mathrm{~m}^{2}$, pero compartidas por más de diez hogares (Contreras y Calorio, 2015). Contrariamente, los valores más bajos de arriendo se localizan en torno al pericentro norte y sur de la ciudad, destacando las poblaciones Jorge Inostrosa y sus alrededores (\$60.000 a 120.000). En resumen, existe una evolución del centro hacia el pericentro en términos del valor del arriendo, lo que evidencia nuevos espacios residenciales de localización de inmigrantes, quienes ven saturado el mercado de alquiler y subalquiler en los sitios tradicionales de inmigración. 


\section{Figura $N^{\circ} 1$. Mercado del arriendo de "piezas o cuartos" en el centro de Santiago}

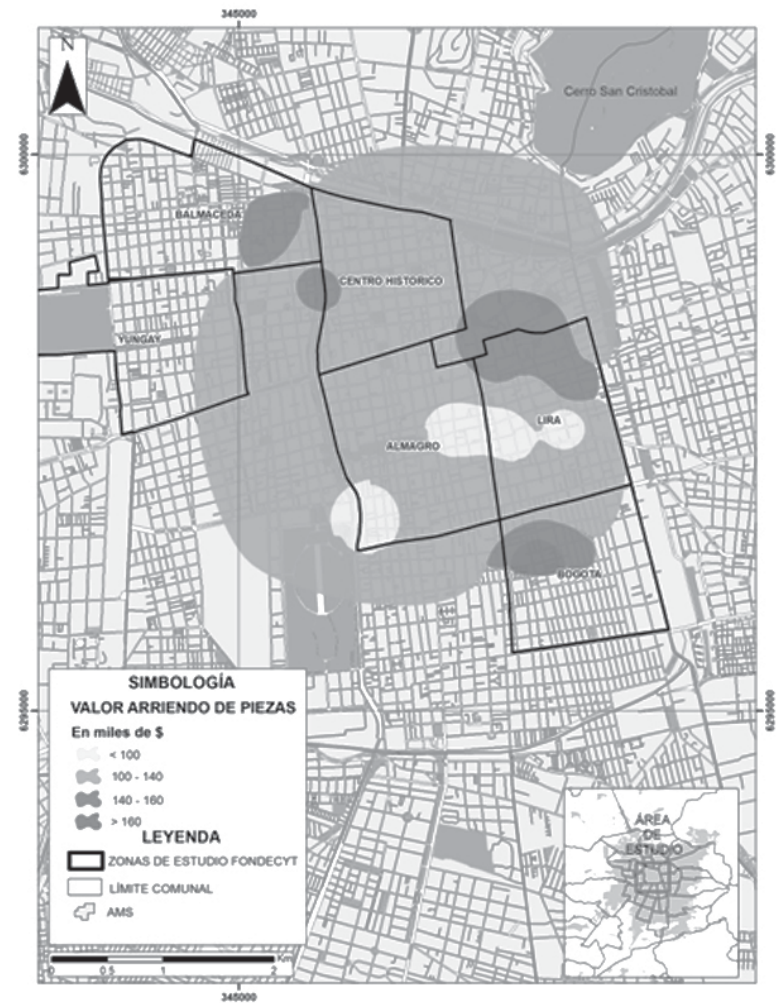

Fuente. A partir de resultados de Encuesta Fondecyt de Iniciación No11121241, 2013.

La nacionalidad del inmigrante se convierte en un código facilitador o limitador de acceso alquiler o subalquiler, ya que entre ellos no se exigen documentos como contratos de trabajos o garantías bancarias: "Lo que pasa es que el dueño de acá es chileno, pero le ha dejado a cargo una señora que es de Perú, entonces se hace más fácil”(inmigrante peruano, residente en Santiago). El relato refleja las estrategias a las que recurren los inmigrantes según nacionalidad. En este sentido una estrategia residencial responde a un compromiso aceptable al que se ve sometido un individuo entre las dificultades contraintes (del mercado, de la vivienda, económicas y financieras, entre otras) y las metas fijadas por el sujeto. También se comprende aquí que una estrategia se configura como la disposición de los medios que aplican los sujetos para lograr un objetivo preciso en un sistema de dificultades (Bonvalet y Fribourg, 1988:2). 
Las estrategias de los inmigrantes según nacionalidad, advierten el sentido de reciprocidad interpersonal de confianza-lealtad que se establecen en el mercado informal de arriendo (Abramo, 2012), y a su vez devela la entrada del sentido de solidaridad a una relación comercial entre ellos (Briceño-León, 2010). Desde los relatos se evidencia una tendencia a coexistir con el mismo, arrendando y subarrendando entre connacionales como estrategias para asentarse en espacios centrales que permiten articular vivienda-trabajo-redes. A su vez, esta estrategia responde a una lógica de organización social que busca superar las limitantes del acceso a la vivienda: "Es una casa de dos plantas sólo bolivianos" (inmigrante boliviana, residente en Iquique). "Son compatriotas también y siempre arrendé a puros compatriotas”(inmigrante peruano, arrendatario y arrendador-intermediario, residente en Santiago).

Aunque existen limitaciones de acceso a viviendas para los inmigrantes latinoamericanos, encontrar residencia en proximidad les resulta rápido, por tanto la decisión de irse es tomada siempre en condición de arrendador o subarrendador. Los plazos de arriendo varían entre meses y décadas. Sin embargo, se reconoce que la flexibilidad que el arriendo y subarriendo se limita a una cierta oferta de viviendas precarias en el mercado del arriendo y subarriendo, muy a menudo informal y gestionado por la población inmigrante (Gilbert, 2010).

\section{Ser inmigrante, negro, discriminalizado y racializado por "blancos pobres"}

Los inmigrantes latinoamericanos que llegan al centro de Santiago e Iquique no sólo se ven enfrentados a los requisitos del marco normativo que regula el mercado formal de acceso a la vivienda, también están restringidos por los requisitos formados socialmente por propietarios y administradores chilenos que ven el mercado del sub-alquiler como mecanismo de ahorro, seguridad social y formas explícitas de discriminar. Los inmigrantes se ven enfrentados a la discriminación, prejuicios y generalizaciones que existen sobre ellos, y los lugares de origen. Los siguientes relatos son esclarecedores:

“Hay mucho racismo acá, de parte de los dueños de casa también. Ellos piensan que todos los colombianos venden droga o se prostituyen” (inmigrante colombiano, área central de Santiago).

"Por ser negro en Iquique cuesta que te arrienden. Tienes que hablar con peruanos para que ayuden, porque aquí hay mucha discriminación y creen que todos somos ladrones o traficantes, ni siquiera saben porque fuimos desplazados de nuestros países (inmigrante colombiano, trabajador formal, residente del área central de Iquique).

“Yo he tocado las puertas y 'hola vengo por el aviso’ ‘no, no arrien- 
do a peruanos, porque son borrachos, porque son esto, porque son cochinos' media vuelta. En otro lado ‘ah no, no se arrienda a extranjero, menos a peruanos”' (inmigrante peruana, área central de Santiago).

"Por ser colombianos nadie les quiere arrendar, por la fama que hay nadie les arrienda. Hay unos tugurios, unos inquilinatos horribles, que ahí se acomodan y les cobran entre $\$ 80.000$ a $\$ 90.000$ por una habitación horrible” (inmigrante colombiana, área central de Iquique).

En Chile, ser negro resulta ser un problema y conflicto racial, especialmente en una sociedad aparentemente blanca. En Iquique, la situación se vuelve mucho más compleja respecto a los entrevistados del centro de Santiago. Lo que se desconoce son las transformaciones en las condiciones sociales, políticas y económicas que llevan por ejemplo a muchos colombianos a cambiar de residencia o bien, ser desplazados forzadamente dadas la "profundización del conflicto armado y las zonas habitadas mayoritariamente por gente negra” (Restrepo, 2004:17). A su vez, lo que la supuesta sociedad chilena de acogida desconoce, es que muchos inmigrantes colombianos de la costa del Pacífico (Valle del Cauca y Chocó) ya son discriminados desde sus sociedades de origen. Muchos de ellos provienen de un Estado colombiano donde la geografía de la discriminación racial hacia los afrocolombianos es histórica. La concentración de inmigrantes afrocolombianos en la Costa del Pacífico, y luego en la Atlántica responde a una subordinación desde las políticas públicas y concepciones culturales dominantes que niega la discriminación racial bajo el supuesto de que los afrocolombianos son pobres al habitar en lugares inhóspitos y difíciles de acceder (Rodríguez, Alfonso y Cavelier, 2008). Por tanto, ¿Qué se podría esperar de una sociedad ignorante en cuanto a cómo los inmigrantes construyen un proyecto migratorio con múltiples barreras desde los espacios de origen?

En el marco globalizador que caracteriza a Chile y en su afán diferenciador respecto al inmigrante latinoamericano, se fraguan representaciones de los inmigrantes que descansan en estereotipos y en atributos imaginados como el negro, el pobre, el ladrón, el violento, el bullicioso, entre otros (Tijoux, 2014)“En el centro a mi hermana no le arrendaban por ser de color. A mí tampoco” (colombiano, residente en el centro de Iquique). Estas representaciones e imaginarios son aspectos que vuelven más compleja la inserción de ellos al parque residencial central y pericentral. Por tanto, el racismo en esta supuesta sociedad de acogida, es reflejo de las "conductas entre grupos humanos que toman la forma del prejuicio, de la discriminación y de la segregación” (Wieviorka, 2009:52), pero que también reflejan a blancos aparentemente ricos y temerosos de los que consideran diferentes. Algunos arrendadores- administradores e intermediarios desean convertirse en propietarios de los inmuebles en los que residen, reconociendo que el mercado del subalquiler es una fuente significativa de ingresos: 
Sí, me gustaría comprarla y refaccionarla y después arrendarla, eso es lo que quiero, tener otra carta sobre la manga porque cuando esté más viejo no voy a poder trabajar” (inmigrante peruano, residente en el centro de Santiago desde hace 8 años, arrendador-arrendatario).

El rol de las redes sociales y familiares en la búsqueda de una pieza es un mecanismo de resguardo frente a la discriminación de muchos entrevistados, especialmente negros. Estas redes sociales y familiares a veces permiten formas menos discriminatorias y racializadas de acceso a la vivienda central. La mayoría de los inmigrantes latinoamericanos entrevistados han encontrado sus viviendas caminando por el barrio o por medio de un familiar, amigo o connacional que le dio el contacto, cambiando su residencia en una micro-escala dentro de la misma zona e incluso, dentro de la misma calle o casa: “Caminamos hasta que conseguimos está casa” (inmigrante colombiana, residente de Iquique), "Lo que pasa es que la fuente es mi hermano que está acá, él tiene contactos y todo eso” (inmigrante peruano, residente en Santiago), “Alquilé una pieza más grande en la misma casa” (inmigrante peruana, Santiago).Los lazos sociales y familiares y los contactos formados a través de ellos, facilitan el acceso a la vivienda, y además al mercado laboral, por la circulación de información "boca a boca” lo cual refiere a la pérdida del anonimato del mercado, que se encuentra reemplazado por relaciones cara a cara como es típico al mercado informal (Abramo, 2010).

De esta manera las redes sociales resultan ser tanto el mecanismo de funcionamiento del mercado informal, como también una estrategia para acceder a la vivienda. Los contratos formados en el mercado informal (de arriendo) (Abramo, 2012), están insertos en una trama de relaciones de amistad y/o parentesco y así es crucial para un inmigrante poseer lazos para acceder al mercado informal habitacional, reflejado en la tendencia de ingresar al país solo si los contactos existen. Sin embargo, casi todos entrevistados llegaron con alguien esperándole y habitaron inicialmente en la vivienda de un miembro de familia, un amigo o conocido: "(Cuando llegué a Iquique) viví un mes en la casa de mi amiga (...) (y luego) me fui arrendar al centro donde vivo actualmente” (inmigrante colombiana, Iquique).

Organizar la composición social de un hogar por medio de contactos y miembros de familia lleva a la formación de unidades familiares no convencionales: "Cuando vino mi hijo y vino mi esposo yo decidí salir de la pieza de mi suegra. Alquilé una pieza más grande (...) que ahora está mi cuñado y ahí vivíamos con mi hijo, me lo trajo mi hermana a mi niño, y con mi esposo" (mujer, inmigrante peruana, Santiago). La situación de buscar arriendo con hijos pequeños resulta difícil para los migrantes tanto por restricciones por parte del arrendador o del intermediano "Decía acá no se traen niños porque el techo suena demasiado y no se puede estar acá abajo” (inmigrante, hombre, peruano, Santiago) como por las condiciones habitacionales, que no se consideran adecuadas para los niños "Es (...) muy complicado buscar una casa con niños, no te reciben parte que las piezas están súper escasas, no encuentras y si encuentras, encuentras 
muchas piezas y con harta gente viviendo y la casa en mal estado" (inmigrante, mujer, peruana, Santiago). Para el inmigrante la proximidad y la distancia constituyen dimensiones especiales y conflictivas en su relación con la ciudad (Márquez, 2014: 52). Se subraya la importancia de los lazos amistosos y familiares como red de seguridad tanto en el sentido de acceso a la vivienda por la información y contactos que facilitan. Este proceso tiene efecto en las decisiones residenciales, es decir, las redes sociales de los inmigrantes se convierten en un sistema parcialmente cerrado, que por medio de circulación de información y conocimiento compartido en relaciones cara a cara dirige los patrones residenciales. Los redes y contactos forman el tejido que los ancla al lugar y a sus habitantes (Márquez, 2013), pero a la misma vez, la construcción social de la realidad limita su conocimiento de otros sectores de la ciudad.

\section{Conclusiones}

Las entrevistas realizadas a inmigrantes latinoamericanos habitando en condiciones de precariedad y accediendo a un mercado de la vivienda central informal e ilegal, devela la existencia de sujetos que acceden a un parque informal por restricción y limitación. La informalidad en las áreas centrales estudiadas refleja una parte constitutiva de la producción de las ciudades y las formas de acceder a la vivienda.

Los inmigrantes precarizados aquí entrevistados - y en el caso particular de inmigrantes colombianos de la Costa del Pacífico-, devienen en sujetos invisibilizados, ignorados y relegados tanto por la sociedad chilena de "acogida", como por su país de origen. Muchos de ellos se encuentran en condiciones sicológicas de origen que se agudizan en una sociedad que es excluyente y racista. La exclusión en el mercado de acceso a la vivienda también se observa en la formalidad, en tanto, el mercado inmobiliario actúa y opera en aquellos inmuebles centrales bien localizados, pero deteriorados, condicionando aún más al inmigrante pobre a posibles desplazamientos bajo procesos de verticalización, renovación urbana o gentrificación. En conclusión, el deterioro y la tugurización también son formas de especulación y rentabilidad.

Asimismo, los inmigrantes se ven sometidos a un mercado informal e ilegal que impone códigos, estrategias y formas desiguales de acceso según origen, año de arribo, color y sexo. Este mercado es tan desigual como el formal, y pone en riesgo a los inmigrantes e incluso nativos pobres, quienes tienen menor poder de negociación. A su vez, la ilegalidad en las formas de arrendar y subarrendar responden a un creciente mercado del alquiler que exige políticas habitacionales y un mayor rol del Estado en comprender que la cuestión migratoria se debe abordar también desde las condiciones de habitabilidad de las personas y las exigencias y cumplimientos éticos de parte de propietarios, administradores e incluso, intermediarios especuladores y racistas. Esto último exige pensar que la inmigración no sólo comprende una dimensión administrativa, más bien visibiliza 
varios problemas: inadecuadas condiciones de habitabilidad de algunos inmigrantes; problemas de salud vinculado a lo anterior; conflictos con hogares nativos o con otros inmigrantes en los espacios compartidos, entre otros. En conclusión, la inmigración y el acceso a la vivienda devela la complejidad del proceso y la necesidad de asumirlo en sus múltiples dimensiones que no son excluyentes, más bien vinculantes entre sí.

Generar mecanismos de subsidios de alquiler en viviendas deterioradas y tugurizadas en las dos áreas centrales, al menos permitiría que las familias inmigrantes vivan en mejores condiciones de habitabilidad, con un precio de alquiler normalizado y regulado, y con posibilidades de movilidad en conformidad con sus necesidades familiares y condiciones económicas. Es necesario definir estrategias que incentiven a los herederos y propietarios a construir viviendas de interés social en áreas centrales con usos mixtos que aseguren la rentabilidad y funcionalidad del mercado y que permitan que estos inmuebles no estén condenados al deterioro, en tanto el deterioro en una sociedad capitalista, es signo de especulación y desigualdad. En esta misma dimensión es necesaria la fiscalización de parte de los gobiernos locales en cuanto a las condiciones de habitabilidad de hogares inmigrantes pobres en tanto, es conocido el patrón de localización de ellos y los mecanismos desiguales de acceso a la vivienda. Establecer multas a propietarios que especulen y renten con las condiciones de habitabilidad de hogares desprovistos de recursos de defensa, aseguraría al menos un compromiso respecto a inmuebles en deterioro. Esto último regularía las exigencias abusivas de parte de arrendadores propietarios, administradores o intermediarios inmigrantes. 


\section{Notas}

1 Los resultados aquí presentados corresponden al Fondecyt de Iniciación (11121241, Conicyt) "Mercado del arriendo y trayectorias residenciales de los precarious urbanos en las áreas centrales de Santiago e Iquique”, realizado entre los años 2012 y 2015. Se agradece la construcción de cartografías a Gricel Labbé y Pedro Palma. En el análisis de las entrevistas se agradece el trabajo realizado por los tesistas Vladimir Venegas, Nicolás Montoya y Nicole Bravo.

${ }^{2}$ En el marco de mercados de tierras, Calderón (1999:14) considera como ilegal "aquella acción (...) que contraviene expresamente las normas jurídicas existentes, sean aquellas señaladas por el código civil (...) o por los códigos urbanísticos (...)” y como informal "las acciones de agentes económicos que no se adhieren a las reglas institucionales establecidas o a quienes se les niega protección, y que desarrollan actividades generadoras de ingresos o beneficios que no están regulados por el Estado en un medio social en que se reglamenten actividades similares". A continuación, vincula lo clandestino al caso donde no se ha solicitado autorización al sector público, diferenciándolo de lo irregular, que si bien aprobado por la autoridad, en su ejecución ocurre en desacuerdo con la legislación. De otros autores, por ejemplo Viana (2007) usa definiciones similares.

${ }^{3}$ Cardoso (2003) ha enfocado su investigación a la irregularidad, pero se plantea la definición por la negación como algo presente en los casos de ilegalidad e informalidad también, dado la condición de conflicto con el marco normativo (estatal) que comparten los términos, y como contrapuntos de términos regular/legal/formal.

${ }^{4}$ En la administración del presidente Sebastián Piñera se exigía a las familias migrantes que desearan postular a beneficios como subsidios habitacionales tener una antigüedad de mínimo 5 años en el país una vez obtenido su certificado de permanencia definitiva, cuestión que se transformó en una barrera administrativa, principalmente para el cierre de campamentos y relocalización de las familias". En http://www.minvu.cl/ opensite_det_20141025131333.aspx. Sitio web revisado el 10 de Agosto 2015.

${ }^{5}$ Dólar al 08 de Septiembre 2015. 1 peso chileno es equivalente a US\$ 690. En http:/ /www.valor-dolar.cl/ 
Polis, Revista Latinoamericana, Volumen 14, No 42, 2015

\section{Bibliografía}

Abrano, P. (2008), "El mercado del suelo informal en favelas y la movilidad residencial de los pobres en las grandes metrópolis: un objeto de estudio para América Latina”. Territorios, 18-19, pp.55-73.

Ídem (2010), "Mercado informal de alquiler: nueva puerta de acceso a los asentamientos populares”. En Escallón, C. Arrendamiento y vivienda popular en Colombia como alternativa habitacional. MESA VIS - Diego Echeverry Campos.

Ídem (2012), "La ciudad com-fusa: mercado y producción de la estructura urbana en las grandes metrópolis latinoamericanas”. EURE 38(114), pp.35-69.

Ídem (2012b), A teoria económica da favela. Río de Janeiro. Observatorio Inmobiliário e de Políticas do Solo (Oipsolo)/Universidad Federal de Río de Janeiro (UFRJ).

Azuela, A. (1993), "Los asentamientos populares y el orden jurídico en la urbanización popular en América Latina”. Revista sociológica 5, pp.12-17.

Bonvalet, C.; Fribourg, A. (1988), Stratégies residentielles. Congrés et Colloques. INED-Plan Construction et Architecture, MELTM-1990. Editions de L'ined, Paris.

Briceño-León, R. (2010), "Diez tesis sobre los pobres y el alquiler de viviendas”. En Escallón, C. (ed) Arrendamiento y vivienda popular en Colombia como alternativa habitacional. MESA VIS - Diego Echeverry Campos.

Canestraro, M. (2013), "Ilegales, irregulares, informales...?: Aportes para un debate sobre el acceso al suelo. Nómadas”. Revista Crítica de Ciencias Sociales y Jurídicas. Núm. Especial: América Latina.

Cardoso, A. (2003), "Irregularidade urbanística: questionando algumas hipótesis”. Cadernos Metrópole, 10, pp.9-25.

Carrión, F. (1992), "Lógica del tugurio. PANORAMA". Revista del banco Central del Ecuador, pp.52-59. http://works.bepress.com/fernando_carrion/ 185

Ídem (2004), Los centros históricos en la era digital. ICONOS 20, pp.3544. Flacso Ecuador.

Clichevsky, N. (1975), "El mercado de tierras en el área de expansión de Buenos Aires y su incidencia sobre los sectores populares, período 19431973”. Tesis de Doctorado, Centro de Estudios Urbanos Regionales-Instituto Torcuato Di Tella. 
Ídem (2003), Pobreza y acceso al suelo urbano. Algunos interrogantes sobre las políticas de regularización en América Latina. División de Desarrollo Sostenible y Asentamientos Humanos, CEPAL, Naciones Unidas. Santiago de Chile. http://repositorio.cepal.org/bitstream/handle/11362/5780/ S0311860_es.pdf?sequence=1

Ídem (2006), Previniendo la informalidad urbana en América Latina y el Caribe. División de Desarrollo Sostenible y Asentamientos Humanos, CEPAL, Naciones Unidas. Santiago de Chile. http://repositorio.cepal.org/ bitstream/handle/11362/5663/S0600001_es.pdf?sequence=1

Contreras, Y.; Calorio, P. (2015), “Migración latinoamericana en el área central de Iquique: Nuevos frentes de localización residencial y formas desiguales de acceso a la vivienda”. Anales de Geografía, vol. 35, №2, pp. 45-64.

Contreras, Y. (2012), Cambios socio-espaciales en el centro de Santiago de Chile: Formas de anclarse y prácticas urbanas de los nuevos habitantes. Universidad Católica de Chile. Tesis para obtención del grado de doctor de Arquitectura y Estudios Urbanos.

Ídem (2011), “La recuperación urbana y residencial del centro de Santiago: Nuevos habitantes, cambios socioespaciales significativos”. EURE 37(112), pp.89-113.

Coulomb, R. (2010), “Arrendamiento urbano, necesidades habitacionales y dinámicas territoriales en México”. En Escallón, C. (ed) Arrendamiento y vivienda popular en Colombia como alternativa habitacional. MESA VIS Diego Echeverry Campos.

Cruz, M. (2000), Reseña “Hábitat popular y política urbana” de Emilio Duhau. Sociológica 15(42), pp.269-273.

Duhau, E. (1995), “Estado de derecho e irregularidad urbana”. Revista Mexicana de Sociología, Universidad Nacional Autónoma de México 57(1).

Fernandes, E. (2002), La influencia del Misterio del Capital de Hernando de Soto. Land Lines 14(1).

Gilbert, A. (2008), Slums, tenants and home-ownership: on blindness to the obvious. IDPR 30(2).

Ídem (2004), “Learning from others: the spread of capital housing subsidies”. International Planning Studies 9(2-3), pp.197-216.

Ídem (2002), “Housing policy and legal entitlements: survival strategies of the urban poor”. En ABEL, C. \& LEWIS, C. (eds.) Exclusion and engagement: social policy in Latin America. London. Institute of Latin American Studies. 
Ídem (2000), "Financing Self-help Housing: Evidence from Bogotá, Colombia”. International Planning Studies 5(2), pp.165-190.

Ídem (2001), “Una casa es para siempre? Movilidad residencial y propiedad de la vivienda en los asentamientos autoproducidos”. Territorios 6, pp.51-73.

Gilbert, A. \& Crankshaw, O. (1999), “Comparing South African and Latin American Experience: Migration and Housing Mobility in Soweto”. Urban Studies, 36(13), pp.2375-2400.

Gilbert, A. \& Varley, A. (2002), Landlord and Tenant: Housing Poor in Urban Mexico.

Herzer, H. et al. (2014), ¿Informalidad o informalidades? Hábitat popular e informalidades urbanas en áreas urbanas consolidadas (Ciudad de Buenos Aires)”. Revista Interuniversitaria de Estudios Territoriales, 4(4), pp.85-112.

Hidalgo, R. \& Torres, A, (2009), “Los peruanos en Santiago de Chile: Transformaciones urbanas y percepción de los inmigrantes”. Polis. Revista de la Universidad Bolivariana, 22, pp.307-326.

Imilán, Walter; Márquez Francisca, Stefoni Carolina (2015), Rutas migrantes en Chile. Habitar, fetejar y trabajar. Universidad Alberto Hurtado.

Jaramillo, S. (1982) ,"El precio del suelo urbano y la naturaleza de sus componentes”. Ponencia presentada al XIV Congreso Interamericano de Planificación de la Sociedad latinoamericana de Planificación. México.

Ídem (2008), “Reflexiones sobre la “informalidad” fundiaria como peculiaridad de los mercados del suelo en las ciudades de América Latina”. Territorios 18-19, pp.11-53.

Kumar, S. (2001), Urban Rental housing and Inclusive Cities. International Conference on Urban Poverty, Marrakech.

Mac Donald, J. (2011), “Ciudad, pobreza, tugurio. Aportes de los pobres a la construcción del hábitat popular”. Hábitat y Sociedad 3, pp.13-26.

Marfarit, D. \& Bijit, K. (2014), Barrios y población inmigrante. El caso de la comuna de Santiago. Revista INVI, vol. 29, N81, pp.19-71.

Marquez, F. (2013), “De territorios, fronteras e inmigrantes. Representaciones translocales en la Chimba. Santiago de Chile”. Chungará, Revista de Antropología Chilena, vol. 45, № 2, pp.321-332.

Peppercorn, I.G. \& Taffin, C. (2013), Rental Housing: Lessons from International Experience and Policies for Emerging Markets. World Bank. Washington DC. 
Restrepo, E, (2004), Conflicto e (invisibilidad). Retos en los estudios de la gente negra en Colobmia. Editorial Universidad del Cauca. Colección Políticas de la alteridad, Popayan, Colombia.

Rodríguez, A. \& Sugranyes, A. (2004), El problema de vivienda de los “con techo”. EURE 91, pp.53-65, Santiago de Chile.

Rolnik, R. (1996), Legislación urbana y mercados informales de tierra en Sao Paulo, Brasil: el vínculo perverso. Mimeo.

Sabatini, F. (2003), "La segregación social del espacio en la ciudades de América Latina”. Serie Azul 35. Pontificia Universidad Católica de Chile, Santiago de Chile.

Smolka, M. (1981), "Precio de la tierra y valorización inmobiliaria urbana: esbozo para una conceptualización del problema”. Revista Interamericana de Planificación $X V(60)$.

Ídem (2003), “Informalidad, pobreza urbana y precios de la tierra”. En Smolka, M. And \&Mullahy, L. (ed) (2007) Perspectivas urbanas. Temas críticos en políticas de suelo en América Latina. Lincoln Institute of Land Policy. EEUU.

Smolka, M. \& Biderman, C. (2011), Vivienda informal: una perspectiva de economista sobre el planeamiento urbano. Documento de Trabajo. Lincoln Institute of Land Policy.

Stefoni (2011), Perfil Migratorio de Chile. OIM. Organización Internacional para los Migrantes.

Sugranyes, A. (2011), “Chabolismo indignante: el hábitat de los que sobran”. Hábitat y Sociedad 2, 27-49.

Tapia, M. (2012), “Frontera y migración en el norte de Chile a partir del análisis de los censos de población”. Siglos XIX-XXI. Revista de Geografía Norte Grande, N53, pp. 177 - 198.

Tijoux, María Emilia (2014), “El Otro inmigrante “negro” y el Nosotros chileno. Un lazo cotidiano pleno de significaciones”. En Boletín Onteaiken No 17 - mayo. Disponible en http://onteaiken.com.ar/ver/boletin17/arttijoux.pdf

Turner, J. (1968), “Housing priorities, settlements patterns and urban development in modernizing countries”. Journal of the American Institute of Planers, 34, pp.354-363.

Un-Habitat (2003), Rental Housing. An essential option for the urban poor in developing countries. United Nations Human Settlement Programme (UN-HABITAT). Nairobi. 
Polis, Revista Latinoamericana, Volumen 14, No 42, 2015

Ídem (2003b), The Challenge of Slums. Global Reporto on Human Settlements. United Nations Human Settlement Programme UN-HABITAT. Earthscan.

Wieviorka, M. (2009), El racismo: una introducción. Editorial Gedisa, S.A., Barcelona, España.

Recibido: 15.11.2015

Aceptado: 20.12.2015 